\title{
Data-driven decision making: implementing analytics to transform academic culture
}

\author{
Anjala S. Krishen ${ }^{1} \cdot$ Maria Petrescu ${ }^{2}$
}

Published online: 9 May 2019

๑) Springer Nature Limited 2019

The role of an academic is to work on four key areasresearch, teaching, service, and outreach. As any faculty progresses through the chain of academic life, the emphasis on each of these areas most likely depends on the factors including the institution, department, and college s/he is working within. At the heart of the pursuit of success in academic life is the attainment of excellence in each of these areasbut how do we measure that? Research abounds on ways that universities measure success, particularly in research productivity and pedagogical innovation and excellence. In Krishen et al. (2019), a knowledge creation framework is proposed which can enable intersectionality and inclusion in academia; this concept was discussed in a recent review from Journal of Marketing Analytics as well (Baker 2019). As discussed in business research, analytics can be used as an objective and metrics-based tool for data reduction and understanding (Petrescu and Krishen 2017; Verhoef et al. 2016; Wedel and Kannan 2016). Analytics and metrics are an efficient way to obtain insights, to monitor, and optimize performance, as well as to maintain competitiveness (Krush et al. 2016; Wilson 2010).

Figure 1 shows two different ways that resources can be allocated within an organization, specifically considering an academic institution. The top-down approach shows three key drivers; those are seniority and rank (seniority-based allocation), demographics (homophily principle), and status quo bias (static culture). Seniority-based allocation follows the idea that power in academia can be gained from earlier access to a higher rank, or accumulated advantage theory (Abramo et al. 2016). This type of allocation is also more

Anjala S. Krishen

anjala.krishen@unlv.edu

1 Lee Business School, University of Nevada, Las Vegas, 4505 Maryland Parkway, Las Vegas, NV 89154, USA

2 Nova Southeastern University, H. Wayne Huizenga College of Business and Entrepreneurship, 3301 College Ave, Fort Lauderdale, FL 33314, USA prevalent in organizational cultures that stress power distance, or accepted inequalities based on hierarchy or other structural systems (Daniels and Greguras 2014; Treviño et al. 2015). The demographics box includes the homophily principle or the idea that social networks and ideas tend to follow a similarity effect (McPherson et al. 2001). According to this principle, individuals have a higher likeness to other individuals because of their perceived similarity with them. The status quo bias box represents the idea that units can use past data and ideas to perpetuate decisions into the future as a tried-and-true shortcut. This type of bias can range from perpetuating resource allocations of the past, promoting a scholarship of a specific type or topic as higher quality, or discounting non-traditional or innovative topics which have not been explored previously in specific units (Sharma et al. 2006).

The bottom-up approach provided in Fig. 1 shows three outcomes: those are performance and productivity (meritbased allocation), demographics (intersectionality and inclusion), and creativity and motivation (transformational culture). Performance and productivity, or merit-based allocation, requires key performance indicators, or targeted analytics (Chapman et al. 2018). To be able to measure performance based on merit, organizations must implement on-going analytics-based data collection and data quality systems (Becker et al. 2018; Ryazanova and McNamara 2016). As a result of this type of resource allocation, the demographics can become more intersectional and inclusive because fairness is increased through transparent, clearly stated, and objective measures. The last box, creativity, and motivation encompasses two key ideas: (1) transformational leadership in combination with diversity leads to higher creativity (Wang et al. 2016) and (2) motivation can be contagious (Krishen 2013) and follows from a carefully implemented organizational culture which serves as a crucial driver of decisions (Lee and Raschke 2018; Lee et al. 2016). A qualified department chair has the potential to implement bottom-up analytics-based decisions and institute resource 

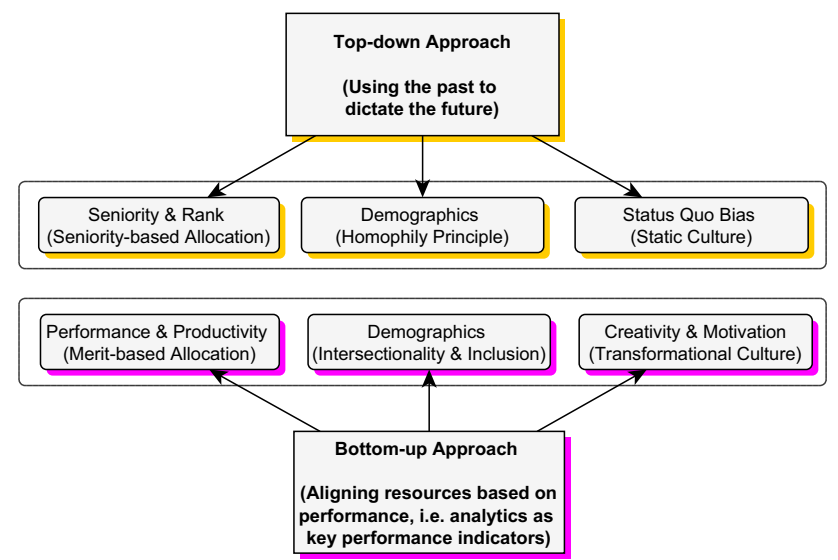

Fig. 1 Combining top-down seniority with bottom-up analytics approaches

allocations which are congruous with performance (Aggarwal et al. 2008; Honeycutt et al. 2010).

The use of analytics in evaluating academic success and effectiveness provides the benefit of a comprehensive performance picture that includes productivity, demographics, as well as creativity and motivation aspects. Analytics can also help with organizing all evaluation elements related to research, teaching, service, and outreach, and with obtaining metrics from objective and subjective sources, as well as qualitative and quantitative data. In combination, universities and departments can use both top-down (the previous decisions and culture) and bottom-up (data-driven analytics) to make more transparent and fair decisions.

\section{References}

Abramo, G., C.A. D’Angelo, and G. Murgia. 2016. The combined effects of age and seniority on research performance of full professors. Science and Public Policy 43 (3): 301-319. https://doi. org/10.1093/scipol/scv037.

Aggarwal, P., L. Rochford, and R. Vaidyanathan. 2008. The Hot Seat: Profiling the Marketing Department Chair. Journal of Marketing Education 31 (1): 40-51. https://doi.org/10.1177/0273475308 324089.

Baker, A. 2019. New Paths for Marketing Relevance: A Review of Marketing and Humanity. Journal of Marketing Analytics. https ://doi.org/10.1057/s41270-019-00048-5.

Becker, T.E., M.C. Kernan, K.D. Clark, and H.J. Klein. 2018. Dual Commitments to Organizations and Professions: Different Motivational Pathways to Productivity. Journal of Management 44 (3): 1202-1225. https://doi.org/10.1177/0149206315602532.

Chapman, K., A.E. Ellinger, K. Filips, and J. Nash. 2018. Benchmarking Marketing Scholar Productivity. Marketing Education Review. https://doi.org/10.1080/10528008.2018.1533412.

Daniels, M.A., and G.J. Greguras. 2014. Exploring the Nature of Power Distance: Implications for Micro- and Macro-Level Theories, Processes, and Outcomes. Journal of Management 40 (5): 1202-1229. https://doi.org/10.1177/0149206314527131.
Honeycutt, E.D., S.T. Thelen, and J.B. Ford. 2010. Evaluating and Motivating Faculty Performance: Challenges for Marketing Chairs. Marketing Education Review 20 (3): 203-214. https:// doi.org/10.2753/MER1052-8008200302.

Krishen, A.S. 2013. Catch it if You Can: How Contagious Motivation Improves Group Projects and Course Satisfaction. Journal of Marketing Education 35 (3): 220-230.

Krishen, A.S., E.A. Robleto, J. Meza, and J. Santana. 2019. From Homophily to Reality: Proposing the Intersectional, Diverse, and Inclusive Knowledge Creation Framework. In Marketing and Humanity: Discourses in the Real World, ed. A.S. Krishen and O. Berezan, 98-117. Newcastle upon Tyne: Cambridge Scholars Publishing.

Krush, M.T., R. Agnihotri, and K.J. Trainor. 2016. A Contingency Model of Marketing Dashboards and Their Influence on Marketing Strategy Implementation Speed and Market Information Management Capability. European Journal of Marketing 50 (12): 2077-2102.

Lee, M.T., and R.L. Raschke. 2018. Freeing "Workplace Prisoners" in Higher Education: Configurations for Collective Knowledge Building and Educational Value Decisions. Journal of Business Research 88: 443-448. https://doi.org/10.1016/j.jbusr es.2018.01.022.

Lee, M.T., R.L. Raschke, and R.S. Louis. 2016. Exploiting Organizational Culture: Configurations for Value Through Knowledge Worker's Motivation. Journal of Business Research 69 (11): 5442-5447. https://doi.org/10.1016/j.jbusres.2016.04.152.

McPherson, M., L. Smith-Lovin, and J.M. Cook. 2001. Birds of a Feather: Homophily in Social Networks. Annual Review of Sociology 27 (1): 415-444. https://doi.org/10.1146/annur ev.soc.27.1.415.

Petrescu, M., and A.S. Krishen. 2017. Marketing Analytics: From Practice to Academia. Journal of Marketing Analytics 5 (2): $45-46$.

Ryazanova, O., and P. McNamara. 2016. Socialization and Proactive Behavior: Multilevel Exploration of Research Productivity Drivers in US Business Schools. Academy of Management Learning \& Education 15 (3): 525-548. https://doi.org/10.5465/ amle.2015.0084.

Sharma, D., N.D. Albers-Miller, L.E. Pelton, and R.D. Straughan. 2006. The Impact of Image Management, Self-Justification, and Escalation of Commitment on Knowledge Development in the Marketing Discipline. Journal of Marketing Education 28 (2): 161-171. https://doi.org/10.1177/0273475306288659.

Treviño, L.J., L.R. Gomez-Mejia, D.B. Balkin, and F.G. Mixon. 2015. Meritocracies or Masculinities? The Differential Allocation of Named Professorships by Gender in the Academy. Journal of Management 44 (3): 972-1000. https://doi. org/10.1177/0149206315599216.

Verhoef, P.C., E. Kooge, and N. Walk. 2016. Creating Value with Big Data Analytics: Making Smarter Marketing Decisions. London: Routledge.

Wang, X.-H., T.-Y. Kim, and D.-R. Lee. 2016. Cognitive diversity and team creativity: Effects of team intrinsic motivation and transformational leadership. Journal of Business Research 69 (9): 3231-3239. https://doi.org/10.1016/j.jbusres.2016.02.026.

Wedel, M., and P.K. Kannan. 2016. Marketing Analytics for DataRich Environments. Journal of Marketing 80 (6): 97-121.

Wilson, R.D. 2010. Using Clickstream Data to Enhance Business-toBusiness Web Site Performance. Journal of Business \& Industrial Marketing 25 (3): 177-187.

Publisher's Note Springer Nature remains neutral with regard to jurisdictional claims in published maps and institutional affiliations. 
Anjala S. Krishen is a Professor of Marketing and International Business at University of Nevada, Las Vegas. Her interdisciplinary research interests include areas within decision making in rich environments, including heuristics and choice set design, e-marketing and social networking, and database marketing. She has over 50 published peerreviewed journal papers, which have appeared in journals such as Journal of Business Research, European Journal of Marketing, Journal of Advertising Research, Psychology \& Marketing, Information \& Management and Journal of Travel \& Tourism Marketing.
Maria Petrescu is an Associate Professor of Marketing at Nova Southeastern University. Her main research areas include marketing analytics and digital marketing. Dr. Petrescu has published articles in journals such as the Journal of Marketing Management, Journal of Product and Brand Management, the Journal of Promotion Management, the Journal of Retailing and Consumer Services, Public Management Review, the Journal of Marketing Analytics and the Journal of Internet Commerce. 